Central Washington University

ScholarWorks@CWU

All Faculty Scholarship for the College of the Sciences

$12-2002$

\title{
Historical Changes in Mid-Water Stands of Common Reed in the Winnebago Pool Lakes, Wisconsin
}

Anthony O. Gabriel

Leo R. Bodensteiner

Follow this and additional works at: https://digitalcommons.cwu.edu/cotsfac

Part of the Climate Commons, Environmental Indicators and Impact Assessment Commons, Fresh Water Studies Commons, and the Terrestrial and Aquatic Ecology Commons 


\title{
Historical Changes in Mid-Water Stands of Common Reed in the Winnebago Pool Lakes, Wisconsin
}

\author{
Anthony O. Gabriel \\ Department of Geography and Land Studies \\ 400 East $8^{\text {in }}$ Avenue \\ Central Washington University \\ Ellensburg, WA 98926 USA \\ and \\ Leo R. Bodensteiner \\ Huxley College of Environmental Studies \\ Western Washington University \\ Bellingham, WA 98225 USA
}

\begin{abstract}
Despite the tolerance of common reed grass to environmental extremes, mid-water stands in the Winnebago pool lakes of central Wisconsin appear to be diminishing. Formerly occupying shoreline locations, water level manipulations subsequent to dam construction beginning in the 1850's have isolated reed stands off shore. These stands have persisted but casual observations indicate that stand size has been declining. To address this perception we obtained an approximately decadal series of aerial photographs dating back to 1937 for four stands in Lake Poygan. Annual records were available for 1986-94. Using image analysis software, we determined shape and size metrics. Changes in stands varied widely, with areal losses ranging from $2 \%$ to $94 \%$. The perimeter showed corresponding losses. Perimeter to area ratio and number of patches indicate that stand loss is characterized by increased fragmentation and shrinking patch size. The pattern of loss appears to proceed through an increase in irregularities along the perimeter, especially along edges facing the summer prevailing winds. This process exposes more of a patch to wind and wave action and eventually results in a division of the patch, culminating in periodic losses of the smallest patches. Despite an overall decrease in stand size, changes in size varied among the years of record with limited recovery occurring during some years.
\end{abstract}

\section{INTRODUCTION}

Common reed (Phragmites australis), a helophytic wetland grass, is a cosmopolitan plant species with a range extending from the tropics into temperate latitudes; in North America it is found into southern Canada (Tucker 1990). The plant tolerates environmental extremes in temperature, $\mathrm{pH}$, water level, substrate anoxia, soil types, and chemistry, and it is capable of rapidly colonizing disturbed environments (Van der Werff 1991). In this study we addressed local perceptions that mid-water stands of common reed were declining in the Lake Winnebago watershed, which is composed partly of four large, shallow lakes in east central Wisconsin. The Winnebago pool lakes, composed of Lake Winnebago (55,772 ha), Lake Butte des Morts $(3,587 \mathrm{ha})$, Lake Winneconne (1,825 ha), and Lake Poygan $(14,102$ ha), drain 16,654 square kilometers and compose $17 \%$ of Wisconsin's surface water area.

Water levels in the upper Winnebago pool lakes have been controlled through dam outflows by the Corps of Engineers since the late 1800's (Wisconsin Department of Natural Resources [WDNR] 1989). As a result of a revised water level management policy instituted in 1982, lake levels in the 
summer are now approximately $1 \mathrm{~m}$ higher than previously occurring levels in the summer, and $10-30 \mathrm{~cm}$ higher in the winter. The Corps maintains water levels within a seasonal range of $1.05 \mathrm{~m}$. Under the current water level management strategy, the water level rapidly increases in the spring and summer, resulting in high lake levels during early plant growth. This is followed by a gradual decrease through the fall to achieve a drawdown in the winter.

Prior to the construction of two dams at the outlets of Lake Winnebago in the 1850 s, the lakes were fertile riverine marshes with dense emergent vegetation (Linde 1975). As late as 1943 the lakes supported a greater diversity and abundance of aquatic macrophytes than any other wetlands in Wisconsin with the exception of the upper Mississippi River; by 1953, abundance and diversity had noticeably declined (Zimmerman 1953). Since impoundment, these large marshes have gradually transformed into large, turbid open-water lakes. Emergent vegetation, particularly cattails (Typha spp.), decreased rapidly after 1930 , as a result of high water levels. The lakes continue to be hypereutrophic and turbid (Lillie and Mason 1983), not only due to agricultural and urban inputs (Northeast Wisconsin Waters for Tomorrow 1994) but also due to increasing exposure and erosion by wave action and ice scour of shoreline substrates formerly protected by vegetation. This is further aggravated by the long fetches and shallow depths (maximum depths 2.7 to 6.4 $\mathrm{m}$ ) of the lakes, which allow frequent resuspension of fine material (Sloey and Spangler 1977).

Prior to impoundment, extensive and dense monotypic stands of common reed have grew in scattered patches throughout the Winnebago pool lakes. During the 1930's operational water levels were increased in the system; consequently, many of these stands now occur off shore (Kahl 1993, Linde 1975). These continually submerged midwater common reed stands, unique with respect to their offshore location, have persisted for decades, despite having been subjected to a variety of stresses, including imposed water level regimes with winter drawdowns, wave action, boating activity, feeding and spawning activities by rough fish, especially common carp (Cyprinus carpio), and competition with intrusive algal growths. However, recent observations suggest that these stands have been diminishing in both size and vigor and that the rate of deterioration in the past 10 to 15 years has been accelerating

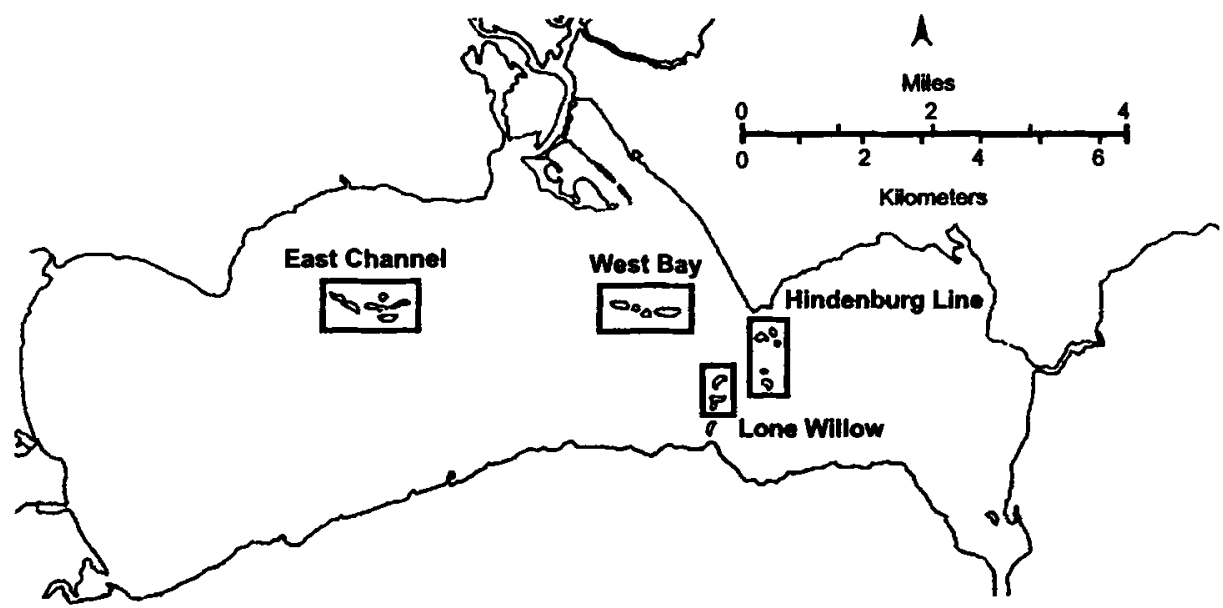

Figure 1. Locations of the four common reed stands in Lake Poygan, Wisconsin. 
(D. Rudebeck, Lake Poygan Sportsman's Club, personal communication, 1997; A. Techlow, Wisconsin Department of Natural Resources, personal communication, 1997). Currently, offshore common reed stands are found in Lake Poygan, Lake Butte des Morts, and Lake Winneconne but have been extirpated from Lake Winnebago.

Our objective was to compile a historical record of changes in common reed stands to address the question of how the spatial characteristics had changed. Because the greatest concern about perceived decreases in common reed coverage was expressed for Lake Poygan, our study focused on this location.

\section{MATERIALS AND METHODS}

\section{Study Sites}

Within Lake Poygan four discrete offshore stands were identified, with each stand consisting of two to several patches of reeds in proximity (Fig. 1). Our study encompassed these four stands, which we identified from west to east as East Channel, West Bay, Lone Willow Island, and Hindenburg Line.

\section{Spatial Characteristics}

To examine changes in spatial characteristics of common reed patches, we compiled and analyzed historical aerial photographs retrieved from the archives of several agencies including U.S. Department of Agriculture's Natural and Resource Conservation Service, Wisconsin Department of Natural Resources, and the University of Wisconsin A.H. Robinson Map Library. Patches of common reed have a particularly good signature on aerial photographs, with distinct contrast to other emergents, and stands are evident at a scale greater than 1:20,000 (Perciasepe and Tippie 1996). The other criterion we used was the date of the photograph, since these common reed stands are only evident during the growing season from 15 June to 15 September. Our goal was to derive at least decadal photographic records of common reed stands to the earliest possible date. We were able to identify and obtain photographs that met our criteria from 1937, 1941, 1950, 1957, 1964, 1971 , and 1981. In addition, we obtained a nearly annual record of aerial photographic slides compiled by WDNR from 1986 through 1994 and 1997.

To enable computer-based analysis, photographs and slides were scanned to create digital image files. Measurements of common reed patches were made using public domain image analysis software available through the National Institute of Health (ImagePro, Scion Corp.). The measurement procedure consisted of establishing and inputting a scale based on the distance between fixed locations within each image and then identifying individual patches. Each patch was outlined using a vector-based process, from which perimeter distance and enclosed area were calculated. A mean measurement was derived from duplicate measurements of each patch. Measurement accuracy was assessed by comparing the two sets of measurements for a number of randomly selected images, which resulted in mean differences in measurements ranging $0.5-1.7 \%$ for various stands and years.

The aerial photographs were analyzed to determine spatial changes in patches of common reeds within each of the four stands based on some of the common metrics used to identify landscape changes, including: 1) areal coverage; 2) number of patches; 3) edge metrics (e.g. perimeter of stands, total perimeter, perimeter to area ratio); and 4) shape metrics such as shoreline development (e.g. Ritters et al. 1992, 1995). 


\section{RESULTS}

Based on the aerial photo analysis, most of the common reed stands showed significant declines in both total area and total perimeters since 1937 (Fig. 2, Table 1). The largest decrease was in the East Channel stand, which decreased by $94 \%$ in area and $83 \%$ in total perimeter. The Hindenburg Line stand lost $65 \%$ in area and $54 \%$ in total perimeter. Decreases in the West Bay stand were less extensive -- only $20 \%$ in area and $2 \%$ in perimeter. The Lone Willow stand has been the most stable of the common reed stands, having lost only $2 \%$ of its area and $3 \%$ of its perimeter.
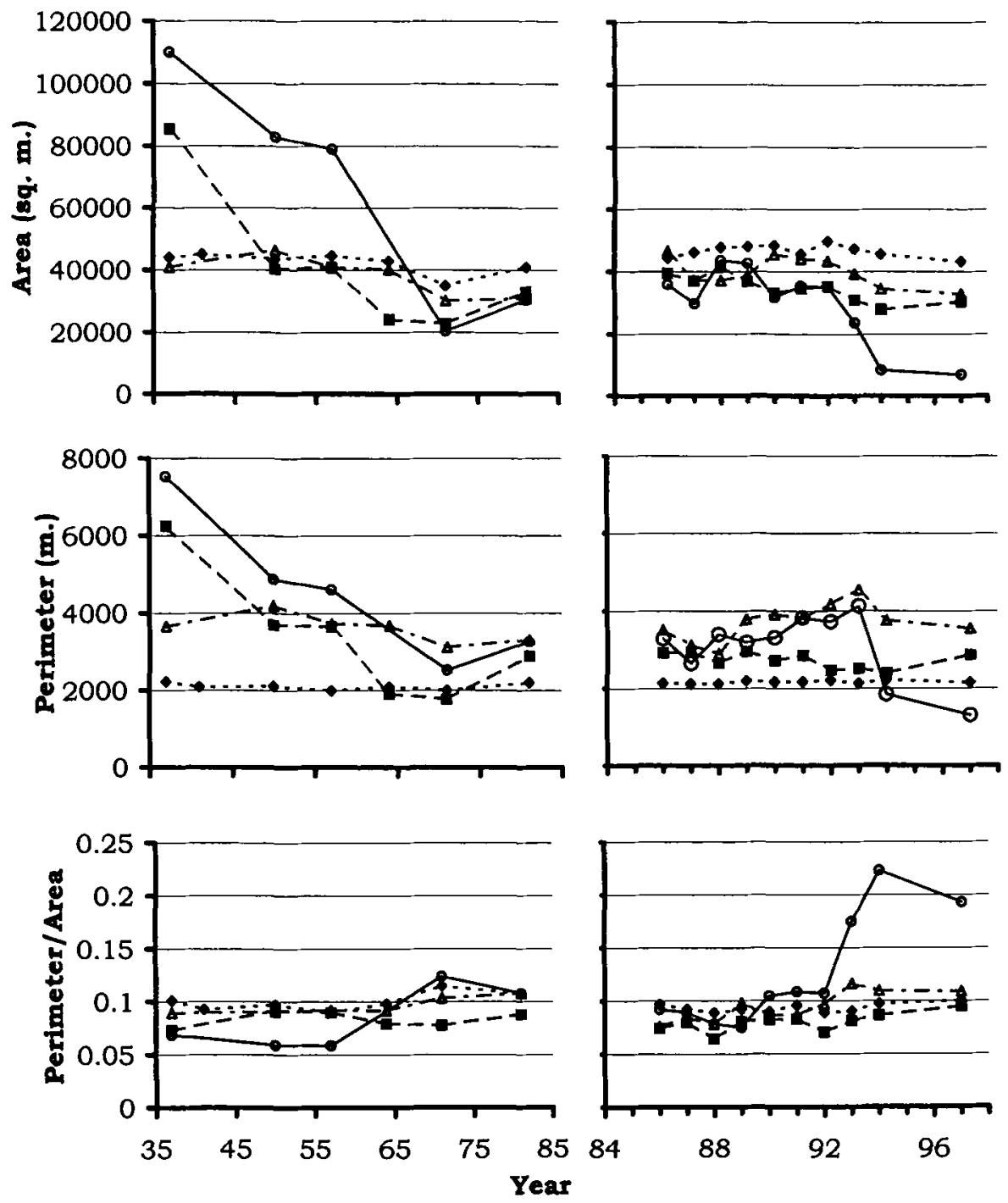

- East Channel

$\rightarrow$-Hindenburg Line

$-\rightarrow$ Lone Willow $\quad-\Delta$ - West Bay

Figure 2. Total area, total perimeter, and perimeter to area ratio of each of the four common reed stands from 1937-81 and 1986-97. 
Table 1. Stem densities and water depths of the four common reed stands in Lake Poygan.

\begin{tabular}{|c|c|c|c|c|c|}
\hline \multicolumn{2}{|l|}{$\begin{array}{l}\text { Stand } \\
\text { characteristic }\end{array}$} & East Channel & Hindenburg Line & Lone Willow & West Bay \\
\hline \multirow{5}{*}{$\begin{array}{l}\text { Stem density } \\
\left(\text { no. } / \mathrm{m}^{2}\right)\end{array}$} & Median & 59 & 60 & 76 & 63 \\
\hline & Inter-quartile range & 38 & 46 & 67 & 79 \\
\hline & $\mathbf{n}$ & 32 & 166 & 48 & 86 \\
\hline & Madimum & 117 & 245 & 171 & 193 \\
\hline & Minimum & 51 & 1 & 9 & 7 \\
\hline \multirow{5}{*}{$\begin{array}{l}\text { Interior } \\
\text { water } \\
\text { depth (m) }\end{array}$} & Mean & 0.93 & 0.74 & 0.73 & 0.56 \\
\hline & SD & 0.11 & 0.16 & 0.19 & 0.20 \\
\hline & $\mathbf{N}$ & 95 & 233 & 126 & 156 \\
\hline & Maximum & 1.25 & 1.18 & 1.30 & 1.08 \\
\hline & Minimum & 0.70 & 0.22 & 0.35 & 0.25 \\
\hline \multirow{5}{*}{$\begin{array}{l}\text { Perimeter } \\
\text { water } \\
\text { depth (m) }\end{array}$} & Mean & 1.06 & 0.88 & 1.06 & 0.81 \\
\hline & SD & 0.15 & 0.26 & 0.17 & 0.29 \\
\hline & $\mathbf{R}$ & 106 & 481 & 362 & 486 \\
\hline & Marimum & 1.30 & 1.52 & 1.48 & 1.30 \\
\hline & Minimum & 0.72 & 0.30 & 0.45 & 0.10 \\
\hline
\end{tabular}

The greatest losses in area in the East Channel stand occurred between 1937-1971, with the largest loss occurring between 1957 and 1971 (Fig. 2). Similarly, the Hindenburg Line stand area also decreased most dramatically between 1937 and 1971, with the heaviest losses being between 1937 and 1950. Both stands experienced resurgences in areal coverage in the $1980 \mathrm{~s}$, peaking in 1988, and subsequently declining from 1989 to the present.

The temporal pattern of change in area was less pronounced in both the Lone Willow and West Bay stands (Fig. 2). Compared to the other two stands, little decline occurred between 1937 and 1957. In fact, the West Bay stand experienced a slight increase between 1937 and 1950 . Both stands experienced similar losses between 1957 and 1971 and then resurged in the early 1980's, as did the East Channel and Hindenburg Line stands. From 1986 through 1997 areal coverage of the Lone Willow stand has been less variable than that of the West Bay stand, the latter showing more variation and sharper decline from 1990 through 1997.

The temporal pattern of changes in total perimeters of each stand was generally similar to that of changes in area (Fig. 2, Table 1). The most extreme losses occurred in the East Channel and the Hindenburg Line stands, while the lowest losses and least variation occurred in the Lone Willow stand. Total perimeter in the West Bay stand fluctuated most through time.

The smallest mean area and mean perimeter of individual reed pacthes presently occur in the East Channel stand, while the largest occur in the Lone Willow stand (Fig. 3, Table 1). Similarly, the East Channel stand had the greatest declines in these measures, despite a brief resurgence in the 1980s. While the characteristics of the average common reed patch in the Lone Willow stand remained steady, a temporary decrease occurred in 1971. Mean patch areas and perimeters have fluctuated in the Hindenburg Line and West Bay stands since 1937, though both have declined to their lowest values for the period of record.

Increased fragmentation, indicated by both the number of patches (Fig. 4, Table 1) and perimeter to area ratios (Fig. 2, Table 1) within each stand, is most apparent in the East Channel stand and least evident in the Lone Willow stand. The historical pattern of fragmentation is particularly interesting in the East Channel stand, which is characterized by periods of increases in 
fragmentation and corresponding losses in area, culminating in periodic losses of the smallest patches and continued area losses and fragmentation in the patches that remained. In addition, the patches that remained in the East Channel stand tended to become smaller, as indicated by mean patch area, mean patch perimeter, and the area and perimeter of the largest remaining patch (Fig. 3). In comparison, the area and perimeter of the largest patch in each of the other stands have varied less, the exceptions being a sharp decline in the Hindenburg Line stand between 1937 and 1950 and peaks in the Hindenburg Line and West Bay stands in 1988. In fact, the perimeter of the largest patch in West Bay has increased between 1937 and 1997, even though the area has remained approximately the same, indicating that the edge of the patch has become more irregular. The area and perimeter of the largest patch in the Lone Willow stand has been the most consistent.
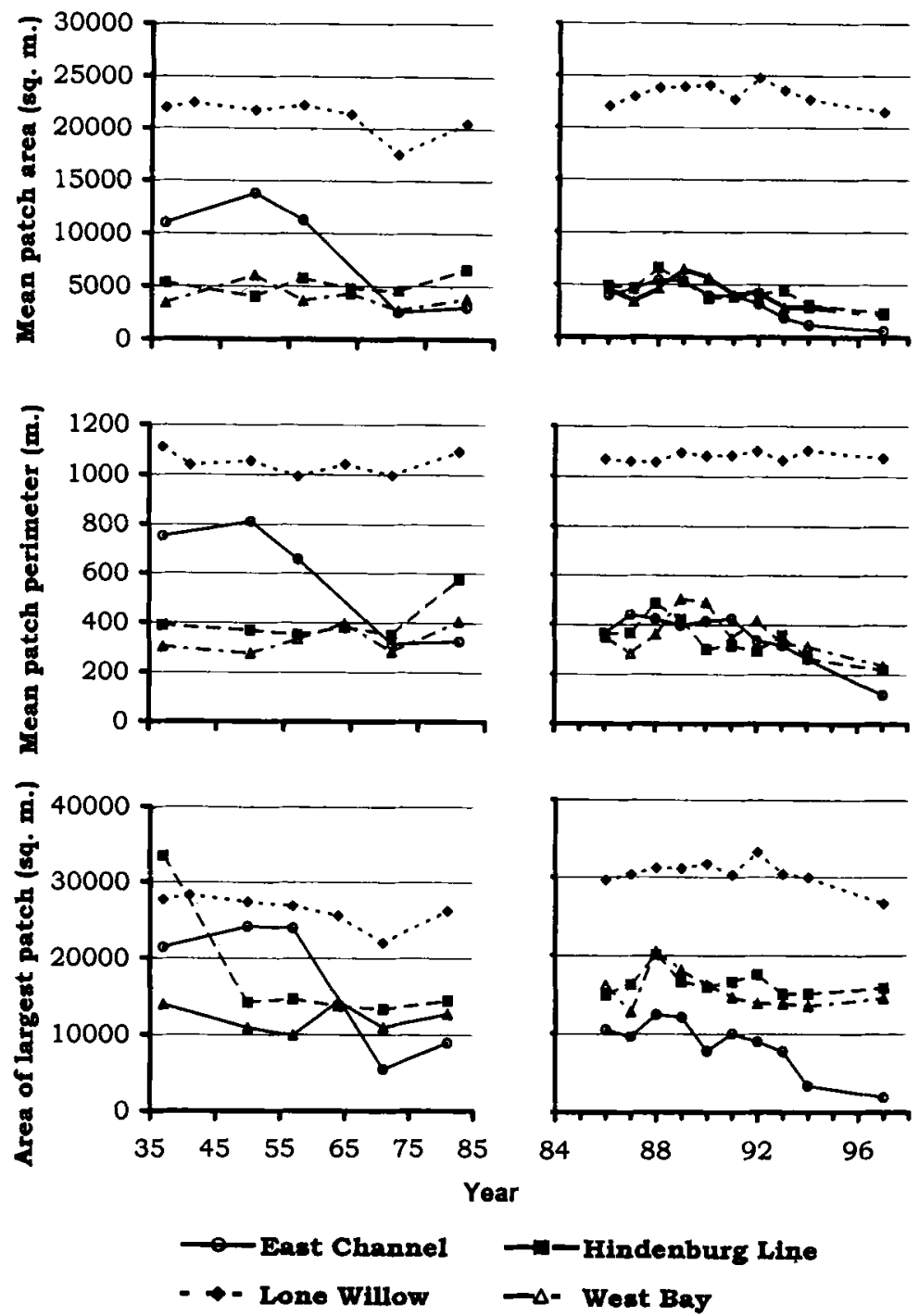

Figure 3. Mean patch area, mean patch perimeter, and area of largest patch of each of the four common reed stands from 1937-81 and 1986-97. 

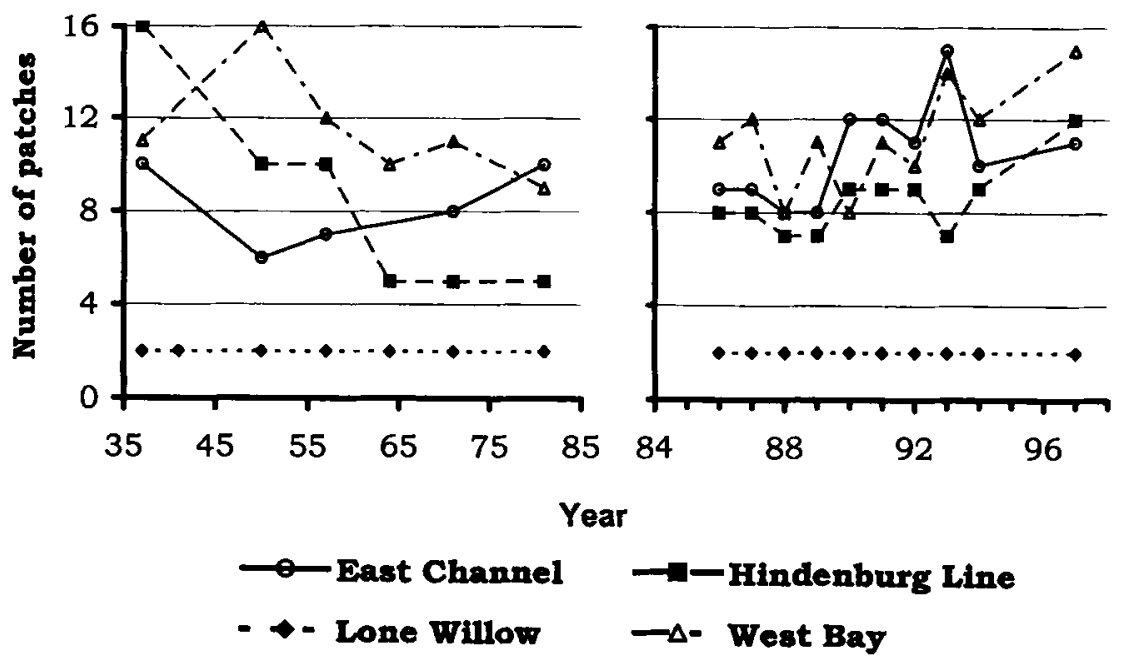

Figure 4. Number of patches in each of the four common reed stands from 1937-81 and 1986-97.

\section{DISCUSSION}

Public perceptions of an overall decline in the size of common reed stands in Lake Poygan were confirmed. However, while the stands occur at midlake locations in relative proximity to each other, we found considerable variation in the changes in spatial characteristics demonstrated by individual stands, ranging from the near extirpation of the East Channel stand to little change in the Lone Willow stand (Figs. 5 and 6). The records indicate that most of this areal loss occurred within the first two decades of the photographic record. This period was subsequent to a change in water level management in 1938 by the Army Corps of Engineers, which resulted in higher water levels during the growing season. Subsequent declines, while of lesser magnitude, have continued to occur in three of the four stands, most notably in the East Channel stand.

Regardless of the amount of change, stand loss appears to follow a consistent pattern. Loss occurs from the outside of each patch inward, with most of the loss occurring along the edges facing west and south, corresponding to the prevailing wind direction. The patch edge becomes less regular, assuming a more ragged outline. Eventually the larger patch is broken into two or more smaller patches. Loss then proceeds through the progressive elimination of the smallest and apparently most vulnerable patches. This pattern of loss is most evident at stand locations that have the greatest exposure to wind and wave action.

The precise relationship between water levels and the changes in spatial characteristics has been examined in detail elsewhere (Gabriel and Bodensteiner 1998, in press). We believe the pattern of reed decline is due to a number of cumulative stresses, many of which relate to the seasonal pattern of water level management that has remained essentially the same over the last 30 years, despite claims of a change in policy in 1982 . Winter drawdown may leave root systems and reproductive structures at intermediate levels more susceptible to damage by ice and destructive sub-freezing temperatures, particularly during severe winters. Ice damage may occur particularly in 
shallow areas, where ice movement could physically disrupt senesced plants and root masses, especially on the outer edges of stands. Root systems below the winter water line are protected and less susceptible to such damage, while higher elevations in the stands may be less susceptible to ice damage as the water table falls below the rhizome mat.

Repair of winter damage is subsequently hampered by the pattern of higher spring and summer water levels coupled with high turbidity from spring runoff, especially during the critical growth period from April to June, which may reduce the availability of light for early plant growth and warming of the sediments. This effectively shortens the growing season for plants and decreases the capacity of these plants to shunt energy into vegetative growth and production of overwinter propagules with larger energy stores (Kahl 1993). In addition, higher water levels may also increase exposure of the weakened plants to wave action and susceptibility to other stresses such as damage by boaters, algal wash, and spawning activity by common carp.

Stresses related to higher spring and summer water levels are greatest in deeper water and affect the plants most weakened by winter damage (i.e., the plants found at intermediate levels at more exposed locations in the stands). A combination of longer durations of high water levels and poor water clarity may also greatly affect expansion and re-colonization of damaged patches. Gradually decreasing water levels in the fall expose successively deeper portions of a particular stand to increasing wave action.

The perception of the role and status of common reeds in wetland vegetation communities is decidedly different between Europe and North America. Because of its rapid colonization of disturbed habitats, persistent nature, and tendency to form monospecific stands, common reed in the U.S. is

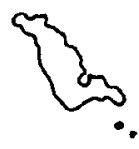

ใ⿺
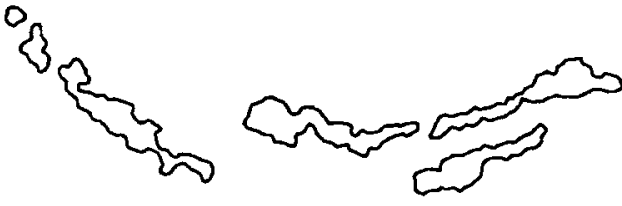

1937
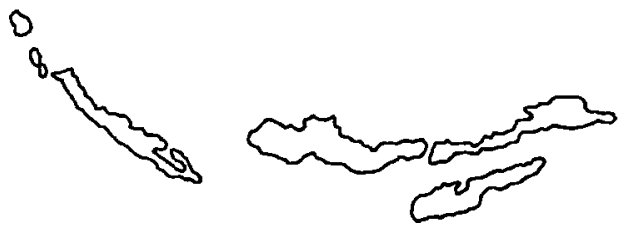

1957

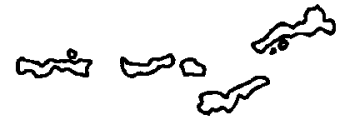

1971
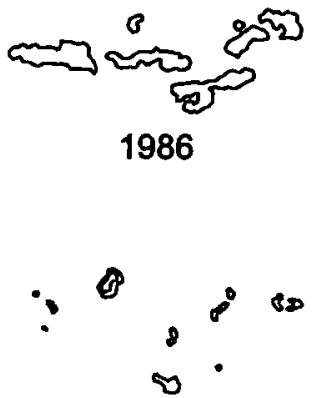

1997

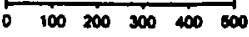

Melers

Figure 5. Historical changes in common reed patches in the East Channel stand based on outlines drawn from aerial photographs. 
often considered a nuisance, as indicated by the preponderance of publications addressing means of eradicating stands (see Marks et al. 1994). In contrast, European literature is greatly concerned with a widespread decline in common reeds, based on documented and perceived benefits to food webs as primary producers and as habitat structure, water quality, and aesthetics. Therefore, research and restoration efforts have been directed toward identifying causative factors and preventing further declines (Ostendorp 1989). Despite the apparently hardy nature of common reeds, restoration efforts have often not been successful, especially under fluctuating water level regimes (Krumscheid et al. 1989). In view of this, potential impacts of the loss of these stands need to be addressed.

The dramatic losses in common reed stands identified by this study have grave implications for the Winnebago lakes system as these stands serve numerous ecological functions. Although limited in spatial extent, attributes suggest that the common reed is a keystone species in the upper Winnebago pool lakes, including: life support for a variety of microbial, invertebrate, vertebrate, and plant and algal populations; maintenance of water quality and geochemical storage, especially with regard to cycling of nutrients, changes in dissolved oxygen, and sedimentation of suspended solids; and, protection of shorelines from wave erosion and prevention of resuspension of fine sediment (Gabriel and Bodensteiner 2000, Kahl 1993, Nichols and Vennie 1991).

Physically, the extensive and persistent mats of rhizomes formed during plant growth stabilize the lake bottom by protecting it from erosion by wave action. These mats remain for years after the plant has died, as observed in former stands on Lake Poygan. In addition, the density of plant stems within stands exerts considerable resistance to water movement, thereby reducing the fetch and decreasing wind-induced turbidity. In Lake Poygan, the substrate on the east sides of the larger stands consisted of much softer, finer material than the sand and hard clay bottom on the side toward the prevailing wind, suggesting that the stands also afford sedimentation sites for suspended solids (Gabriel and Bodensteiner 2000).

Finally, the methodology used by this study to assess historical change of common reed stands has utility for future projects. Other researchers have noted the strong photo signature of common reed stands on aerial photographs (Perciasepe and Tippie 1996) and have used low altitude vertical aerial photographs to assess historical changes (e.g. Krumscheid et al. 1989, Havens et al. 1997). However, analysis has usually been limited to two to three decades due to the lack of older photographic records (Ostendorp 1989). With

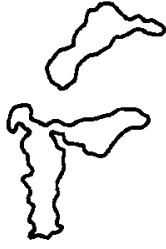

1937

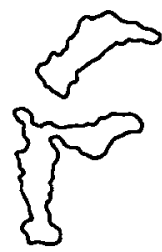

1957

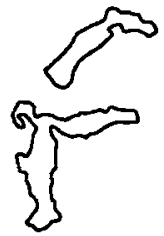

1971
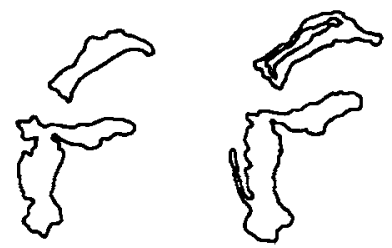

1986
1997

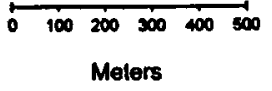

Figure 6. Historical changes in common reed patches in the Lone Willow stand based on outlines drawn from aerial photographs 
the increasing number of government agencies maintaining aerial photographic libraries, researchers have ever increasing access to a variety of sources of records of historical change. In addition, access to affordable scanning technology enables researchers to digitize and retain images of aerial photographs at much lower costs. The image analysis software, NIH Image Pro, which may be used to calculate changes in area and perimeter length, further reduces the time and cost of such analysis in comparison to either traditional aerial photo interpretation methods or using geographic information systems (GIS). As NIH Image Pro may be used to analyze images relative to the number of pixels that correspond to a known distance of a feature common to data sets, researchers are able to accurately analyze images at different scales and in different formats (e.g. maps, slides, and aerial photographs) without the effort and cost associated with photogrammetrically rectifying and digitizing these various sources so that they might be used in a GIS analysis.

\section{ACKNOWLEDGMENTS}

This work was funded by a Wisconsin Department of Natural Resources Lakes Planning Grant, the Lake Poygan Sportsman's Club, and faculty development grants from University of Wisconsin-Oshkosh and Western Washington University. Thanks to D. Rudebeck, A. Techlow, R. Kahl, N. Dvoracek, B. Benninghoff and L. Yurk.

\section{LITERATURE CITED}

Bodensteiner, L.R., and A.O. Gabriel. In press. Response of mid-water common reed stands to physical environmental conditions in Lake Poygan, Wisconsin. Aquatic Botany.

Gabriel, A.O. and L. Bodensteiner. 2000. Restoration and Ecosystem Functions of Common Reed Stands in Lake Poygan, Wisconsin. Wisconsin Department of Natural Resources Lake Protection Grant Report. Geo-ecology Research Group Research Report 2. Ellensburg: Central Washington University. 122 pp.

Havens, K.J., W.I. Priest III, and H. Berquist. 1997. Investigation and longterm monitoring of Phragmites australis within Virginia's constructed wetland sites. Environ. Manag. 21:599-605.

Kahl, R. 1993. Aquatic Macrophyte Ecology in the Upper Winnebago Pool Lakes, Wisconsin. Wisconsin Department of Natural Resources Tech. Bull. 182. Madison, Wisconsin.

Krumscheid, P., H. Stark, and M. Peintinger. 1989. Decline of reed at Lake Constance (Obersee) since 1967 based on interpretations of aerial photographs. Aquat. Bot. 35:57-62.

Lillie, R.A. and J.W. Mason. 1983. Limnological Characteristics of Wisconsin Lakes. Wisconsin Department of Natural Resources Tech. Bull. 138. Madison, Wisconsin.

Linde, A. 1975. Report on Preliminary Fox and Wolf River Lakes Vegetation Studies. Fox-Wolf Lakes Habitat Deterioration Exploratory Studies. Wisconsin Department of Natural Resources, Oshkosh, Wisconsin.

Marks, M., B. Lapin, and J. Randall. 1994. Phragmites australis (P. communis): threats, management, and monitoring. Nat. Areas J. 14:285-294.

Nichols, S.A. and J.G. Vennie. 1991. Attributes of Wisconsin Lake Plants. 
Wisconsin Geological and Natural History Survey Information Circular 73. Madison, Wisconsin.

Northeast Wisconsin Waters for Tomorrow. 1994. Toward a Cost-Effective Approach to Water Resource Management in the Fox-Wolf River Basin: A First Cut Analysis. Green Bay, Wisconsin.

Ostendorp, W. 1989. Die-back of reeds in Europe - a critical review of literature. Aquat. Bot. 35:5-26.

Perciasepe, R. and V.K. Tippie. 1996. Coastal Restoration and Protection: Lessons Learned. Coastal America Technology Transfer Report. Coastal America, Silver Spring, Maryland.

Ritters, K.H., R.V. O'Neill, C.T. Hunsaker, J.D. Wickham, J.D. Yankee, S.P Timmins, K.B. Jones, and B.L. Jackson. 1995. A factor analysis of landscape pattern and structure metrics. Lands. Ecol. 10:23-39.

Ritter, K.H., B.E. Law, R.C. Kucera, A.L. Gallant, R.L. DeVelice, and C.J. Palmer. 1992. A selection of forest condition indicators for monitoring. Environ. Monit. Assess. 20:21-33.

Sloey, W.E. and F.L. Spangler. 1977. The Trophic Status of the Winnebago Pool Lakes. Fox Valley Water Quality Planning Agency, Neenah, Wisconsin.

Sukopp, H. and B. Markstein. 1989. Changes of the reed beds along the Berlin Havel, 1962-1987. Aquat. Bot. 35:27-39.

Tucker, G. C. 1990. The genera of Arundinoideae (Graminae) in the southeastern United States. J. of the Arnold Arboretum 71:145-177.

Van der Putten, W.H. 1997. Die-back of Phragmites australis in European wetlands: an overview of the European Research Programme on reed dieback and progression (1993-1994). Aquat. Bot. 59:263-75.

Van der Werff, M. 1991. Common reed. p.172-182. In: Ecological Responses to Environmental Stresses (J. Rozema and J.A.C. Verkleij ,eds). Kluwer Academic Publishers, Amsterdam.

Wisconsin Department of Natural Resources. 1989. Winnebago Comprehensive Management Plan. FW-19-P-1. Oshkosh, Wisconsin.

Zimmerman, F.R. 1953. Waterfowl Habitat Surveys and Food Habitat Studies, 1940-1943. Wisconsin Conservation Department, Madison, Wisconsin. 